$\begin{gathered}\text { EPiC Series in Education Science } \\ \text { Volume 1, 2017, Pages 38-45 }\end{gathered}$
$\begin{gathered}\text { AUBEA 2017: Australasian Universities Build- } \\ \text { ing Education Association Conference 2017 }\end{gathered}$
Education
Science

\title{
Building STEM Skills in Built Environment Education
}

\author{
P. McLaughlin ${ }^{1}$, B. Kennedy ${ }^{1}$ \\ A. Gulluzzo ${ }^{1}$ M. Donnato ${ }^{2}$ \\ ${ }^{1}$ RMIT university, Melbourne, Australia \\ ${ }^{2}$ Deakin University, Geelong, Australia. \\ Patricia.mclaughlin@rmit.edu.au, Belinda.kennedyermit.edu.au
}

\begin{abstract}
Australia is on the cusp of a range of global megatrends across technology, society, the economy, and the environment which are changing the world of work for future graduates beyond current recognition. Digitisation, technology and automation are requiring new skills at a rate of exponential change. Many of these skills have traditionally been classified as skills related to STEM disciplines. But future employability is now linked to the growing demand for 21st century STEM skills beyond existing traditional understandings of STEM. It will not only be STEM graduates who will need 21st century skills of discipline literacy, adaptive thinking, proficiency in coding and technology, utilising a design mindset, complex problemsolving and analytical thinking skills. All students, including built environment graduates, will need adaptive thinking about their worlds and exposure to $21^{\text {st }}$ century STEM skills and understandings. This research work by members of the OLT funded STEM Ecosystem illustrates the development of STEM skill learning opportunities for built environment students. The learning opportunities discussed in this paper are archetypes of 21 st century skills and featured engagement with diverse cohorts of students, practice-oriented learning, STEM literacy, adaptive thinking and disciplinebased core knowledge. The results from 46 student interviews indicate the relevance of $21^{\text {st }}$ century STEM skills for built environment students, and the increased skill set of built environment students involved. The results and outcomes of this research have the capacity to provide industry with built environment graduates who are not only technically skilled but future $21^{\text {st }}$ century STEM work-enabled.
\end{abstract}




\section{Introduction}

Australia is on the cusp of a range of global megatrends that are changing the way people live, work and acquire knowledge. Megatrends across technology, society, the economy, and the environment are changing the world of work for future graduates beyond current recognition (CSIRO 2016). Digitisation, technology-fuelled disruption and automation are requiring new skills at a rate of exponential change. This disruption arising from the interaction of technological change and increasingly porous global boundaries is already creating a brave new world of work reliant upon $21^{\text {st }}$ century STEM skills (Callander, 2015; Gratton, 2015). This disrupted future holds exciting opportunities for universities and their graduates, but also poses complex, urgent questions. To imagine the university built environment curriculum, with its current siloed approach and disciplinebased teaching and learning, is immune from these trends is naïve.

The demand for graduates with skills and understandings that match $21^{\text {st }}$ century workplaces is escalating (Montt, 2016; Productivity Commission, 2016). The term $21^{\text {st }}$ century skills refers to a set of knowledge, skills, work habits and character traits that are critically important to success in today and tomorrow's world and workplaces (Siekmann \& Korble, 2016; Binkley et al, 2012). Deloitte (2015) and West (2012) note the intrinsic overlap between $21^{\text {st }}$ century skills and STEM skills and ways of thinking, and provide evidence that employment success across a wide range of current and future industries is related to $21^{\text {st }}$ century STEM ways of thinking such as analytical skills; logical and critical thinking; systematic, structured understandings; evaluative approaches; independent reasoning with sceptical and evidence-based rational approaches to problem solving and innovative, creative and lateral solutions. The Organisation for Economic Co-operation and Development (OECD, 2014) has highlighted the supply of professionals with these skills, as an urgent global problem. This increasing global demand for graduates with $21^{\text {st }}$ century STEM skills is a result of a number of factors, including:

- the growing use and impact of information and communications technologies inter-woven across all future work;

- the high rate of innovation fuelling rapid application of advances in multi-disciplinary products and processes; and

- the shift to more knowledge-intensive industries and services, not reliant upon single traditional discipline responses.

The traditional understanding of STEM has long been viewed as beyond built environment and focussed upon careers in science, technology, engineering and mathematics (Sanders, 2009; Binkley et al, 2012; World Economic Forum, 2015). However simply providing more STEM graduates in existing disciplines to the exclusion of other disciplines such as built environment will not address future domestic and global workplace needs, nor contribute to Australia's economic prosperity (OCS 2016). There is a growing demand for 21 st century STEM skills beyond existing traditional understandings of STEM disciplines. It will not only be STEM graduates who will need 21st century skills such as discipline literacy, adaptive thinking, proficiency in coding and technology, utilising a design mindset, complex problem-solving and analytical thinking skills. All students, including built environment graduates, will need adaptive thinking about their worlds and exposure to STEM skills and understandings to navigate future employment. Evidence indicates that building $21^{\text {st }}$ century STEM skills across the total population will be critical in helping to support innovation and productivity regardless of occupation or industry (PWC 2016). As Finkel (2016) noted, "all graduates need to be equipped with STEM skills to enable their futures in a changing world: STEM skills are needed for all jobs."

The Australian Government (OLT) funded STEM Ecosystem project (Mclaughlin et al, 2015) identified the need for all students, especially built environment disciplines to undertake opportunities to build their STEM cross-disciplinary skills. A key recommendation of the project was- 
- That STEM skills and the involvement of non-STEM discipline students in crossdisciplinary projects and learning approaches be enhanced through practice-oriented, creditbased cross-disciplinary learning innovations, workshops, studios, challenges and courses (McLaughlin et al, 2015 p.9).

The project noted that effectiveness of impact upon lifelong learning is more likely to be achieved if students are exposed to these opportunities during their discipline-based studies. Such exposure lifts interest, understanding and creates a domino effect of change. Existing evidence indicates that nonSTEM students engaging with STEM learning and teaching opportunities (even for short periods of time) develop their critical thinking, problem solving, analytic capabilities, adaptive thinking, quantitative analysis, imagination and curiosity skills, all critical skills in future workplaces (Freeman, 2013; Healy et al, 2013).

Healy et al, (2013) estimate that 44 per cent of jobs in Australia, many in built environment areas, are potentially at high risk of automation and computerisation and that many new jobs will also be created by technology. Australia is entering a period of rapid transition where STEM $21^{\text {st }}$ century skills will be vital for employability and lifelong learning and satisfaction. The need to change learning and teaching approaches to match such future workplaces and identify clever delivery of $21^{\text {st }}$ century STEM skills to all students, including built environment students, is now urgent.

\section{The $21^{\text {st }}$ Century STEM Skills}

The concept of $21^{\text {st }}$ century skills refers to a comprehensive and grounded skills framework that displays all of the literacies and employability skills desired by employers and applicable to lifelong learning and futures in a globalised, changing world (Siekmann \& Korbel, 2016). Binkley (2012) in an analysis of such frameworks noted the importance of ways of thinking as underpinning much of the framework. More recently the World Economic Forum (2015) grouped the $21^{\text {st }}$ century skills into foundational literacies such as discipline literacy, and competencies and qualities such as curiosity, adaptability and critical thinking/problem solving. West (2012) describes $21^{\text {st }}$ century skills as knowledge, skills and ways of thinking so that graduates can function in a "STEM-core" world.

Whilst the nomenclature of $21^{\text {st }}$ century STEM skills is constantly refined, what is not under debate is that today's students need different skills from those taught to previous generations. Yet much of our teaching and learning still present in university curricula reflects pedagogy and discipline-based knowledge that is not encompassing of future $21^{\text {st }}$ century skills. Skills such as critical literacies, initiative, technological literacy and adaptive design are essential to success in modern workplaces and adult life (Siekmann et al, 2016), yet are often buried within discipline-based contexts. As a result most students have little or no exposure to such skills in any developmental way and most students acquire such skills in an ad-hoc manner.

A number of researchers have linked $21^{\text {st }}$ century skills and STEM skills as interchangeable (Binkley et al, 2012; World Economic Forum, 2015). The concept of STEM has a number of meanings, but STEM itself is now recognised as a meta-discipline in its own right- the integration of formerly separate disciplines into a field of study that embraces $21^{\text {st }}$ century skills (Blackley et al, 2015; McLaughlin \& Kennedy, 2016). Lantz (2009) refers to STEM as a "discipline created on the integration of skills and knowledge into a new whole" and talks of a pedagogical approach of STEM that is of purposeful design and inquiry, combining technical design with inquiry to acquire $21^{\text {st }}$ century skills. Whilst there is still a place for the existing discipline-based approaches, as Williams et al (2013) note, the pressing need for an integrated approach that positions all students and learners for employability and learning futures is escalating. This paper illustrates how built environment students can access $21^{\text {st }}$ century STEM skills in a cross-disciplinary team environment. 
The relevance of $21^{\text {st }}$ century STEM skills for all students cannot be underestimated in an age when vast quantities of information are available instantaneously and outdated almost immediately, the ability to deal nimbly with complex and often ambiguous knowledge is far more important than an accumulation of facts. In a flat, connected world, built environment graduates will need the cultural awareness, and global contacts essential for a global market place (Navitas, 2013). As Barber et al (2013) indicate, most graduates will either work in an international company or spend part of their career overseas - to be global business savvy, to be culturally competent, is no longer a 'nice to have', it's a competitive advantage.

These imperatives are not for selected STEM disciplines: they are for all students. All built environment students need to have at least some experience in cross-disciplinary practice-oriented $21^{\text {st }}$ century STEM learning opportunities to develop these skills and competencies. The following section discusses the incorporation of built environment disciplines into $21^{\text {st }}$ century STEM skills learning opportunities.

\section{Developing $21^{\text {st }}$ Century STEM skills in Built Environment Learning}

Built environment disciplines are often seen as opportunities to induct students into the content of the discipline, not as opportunities to develop cross-disciplinary skills or develop solutions to complex multi-disciplinary problems using $21^{\text {st }}$ century skills. Whilst there is a place for specific disciplinebased education, it is not the only type of education students of the future should be offered. What is required is the application of STEM skills and ways of thinking to multidisciplinary understandings and solutions. A paradigm shift away from discipline-based knowledge transference towards $21^{\text {st }}$ century STEM skills for the future (Kennedy \& McLaughlin, 2016) encompasses -

- cross-disciplinary understandings/competency

- discipline "literacy" skills

- social intelligence

- STEM design mindset

- $\quad$ sense-making/adaptive thinking

- cognitive load-management

- ways of thinking (problem-solving, critical analysis, creativity, innovation)

- ways of working ( collaborative, communication)

- ICT literacy

- Citizenship ( global competence and cultural responsibility)

The Sustainable Systems Course at RMIT (MIET 2380) created opportunities for students from different discipline-based degrees (engineering, health, education and building) to work alongside industry practitioners in cross-disciplinary teams to design, present and build (in 2018), innovative sustainable sanitation solutions for the Yasawa communities in Fiji.

The course was conducted in semester two, 2016 and built upon existing STEM Ecosystem work in the College of Science, Engineering and Health at RMIT. A total of 46 students from engineering, built environment, education and health disciplines enrolled into the course. As a cross-disciplinary course, all students received credit for either elective or core course study. Students were given the project brief and information by the industry people in the Yasawas, Fiji, including Barefoot Resorts. They worked in project teams to create and discuss potential solutions, and checked their ideas against the industry people via skype and email. The nature of the project required $21^{\text {st }}$ century STEM skills with discipline-based literacy and content input provided by the students and cross-disciplinary problem solving, critical analysis and creative innovation. The aim to build cross-disciplinary 
understandings, $21^{\text {st }}$ century skills and global competence was also introduced during classroom sessions.

The students and staff set up a Google site and drop box, which were used as a virtual "meeting place" and "exchange". Evaluation and feedback was built into the learning process, with set time devoted each week to evaluation of the design and development processes and a particular $21^{\text {st }}$ century skill session related to the Fiji project conducted each week at the commencement of the class. This opportunity for reflective practice enabled students to organize their learning and ways of working to include collaboration and feedback. It also allowed for adaptive thinking around the problem and learning from their peers or "sense-making" of the issues.

The course was conducted in two workshops each week of 2 hours duration for one semester. Students came from diverse discipline backgrounds with differing levels of knowledge and skill. Classes were built around 21st century skills development: problem-solving, adaptive thinking, critical analysis, STEM design and literacy, and social and emotional intelligence. The majority of the students, and all of the built environment students were in the second year of their studies. Students who participated in this course have the opportunity to travel to Fiji under Endeavour and NCP grants to collect further data, build their ideas in practice and participate in local community activities in 2018/19. At the conclusion of the course, all students were interviewed in their teams about their experiences and understanding of $21^{\text {st }}$ century STEM skills and their ability to build such skills in their team project. A total of six questions were asked of each group.

One of the key $21^{\text {st }}$ century STEM skills that the course aimed to develop was discipline literacy and STEM design mindset- that is using all the skills of the team (engineering, construction, health and education) to design a solution. Students felt the opportunity to engage with other students strengthened their discipline literacy and depth of discipline understanding. Comments included:

"When I had to explain the water table and the depths to others who didn't understand it, I realised I had to use examples that they would get- that was hard and forced me to think about engineering differently"

"Well, the construction guys all knew things that I didn't, maybe their background, so I actually had a bit to learn from them really-so it was good"

This construct of STEM literacy is multi-faceted and includes the development of competencies for lifelong learning, including an ability to engage in reasoning about complex societal issues (Sabelli, 2006). Students interviewed in this course agreed that they were required to reason in their discipline to advance the team thinking:

"Basically you need to listen to others and their arguments to get the results. None of us alone could do this- really X (the education student) was able to get us to say our own view from our own background, like engineering, and then we sort of listened to others and made some better answers from that."

"Really I knew nothing about health or building and now I do!"

A critical $21^{\text {st }}$ century skill is ways of thinking (problem-solving, critical analysis, creativity, innovation) that advance the students along a continuum of learning. Siekmann et al, (2016) indicate that such a learning process provides a training ground for future workplaces and employment. There is evidence that providing diverse disciplines with opportunities to work together allows innovation and creativity:

"I wouldn't have thought of what the health student did-I was like-really, is that true, because we had better put it into the answer"

West (2012) describes $21^{\text {st }}$ century skills as knowledge, skills and ways of thinking so that graduates can function in a "STEM-core" world. He describes future workplaces as being places of STEM-core work that requires research, enquiry; problem solving; technical skills including observation, experimentation and quantitative skills; presentation and teamwork. All students need to be exposed to these STEM core skills beyond their discipline. When asked about their contribution to 
these skills areas the construction students felt they had learnt new ideas, skills and thought processes, and had contributed to others understanding and appreciating their role:

"It gave me some skills in experimenting with solutions, like the sand filtration set-up. Then we didn't use it, so I guess I learnt a lot about planning and experimenting and yeah, some technical science/engineering skills. I mean I am not an engineer, but now I have some clue about what they could help with and help the answers."

"Yes, I definitely learnt some new skills like you say "stem" but really it was just that they were able to let me have some ideas that we could trial out."

Students were experimenting and developing technical thinking skills beyond their construction discipline as detailed by West (2012) in his analysis of STEM-core skills. Freeman (2013) also indicated that even some small exposure to STEM skills and ways of thinking would create change in thinking amongst non-STEM students and the student interviews in this course supported this:

"I guess my frame of reference changed, when I realised I had to learn some new things and I just couldn't design the answer all alone-I needed the engineer to help, especially with the drawing parts. I definitely changed my ideas and thinking"

The concept of $21^{\text {st }}$ century skills also includes ways of working collaboratively and with developing social intelligence. When asked about their team's maturity and performance, students noted the growth in stages of maturity:

"At first, everyone just put forward their ideas and some people did not accept the skills of others, then as the course went on we learnt new things and changed our behaviour I guess"

"I wasn't sure of my team- like I thought it would be helpful to put all the building students in one group at first, but that may not have worked."

Both Navitas, (2013) and Barber et al (2013) have stressed the importance of students tackling complex problems that are beyond their current discipline and which represent a wider world view than the domestic applications. By providing such a problem as the sanitation issues in the Yasawas, students were unable to draw upon local knowledge and had to design creative and adaptive ways of accessing global information not readily available.

"Of course it is important to help others, but it is not just helping- we are learning too"

"Who really cares about Fiji- I wonder if we should look at problems here in Australia....easier for communication and information"

Lantz (2009) refers to STEM as a "discipline created on the integration of skills and knowledge into a new whole" and Sanders (2009) talks of a pedagogical approach of STEM that is of purposeful design, combining technical design with scientific inquiry to acquire $21^{\text {st }}$ century skills:

"This was great- learning new things that you wouldn't get taught in building classes"

"I have learnt so much about engineering and technology, and maybe thinking about design all the time when getting the answers."

Williams (2011) has noted the pressing need for an integrated approach that positions all students and learners for employability and lifelong learning futures, whilst acknowledging the need for discipline based knowledge to fuel discipline literacy. In this study students were very aware of this future "learning":

"I think this will help me get a job-I am able to work with engineers, health students and education students on a shared project that will probably be built in Fiji in 2018-2019, so that is great for me. Plus, I have a whole new idea of what these others can do and really they were able to do things that I couldn't do, so that was very useful.... if you only do it from your perspective, then that doesn't take into account things like health of the people there" 
The proliferation of technology and increased global interconnectedness is forcing employment changes to enable further flexibility and virtualisation of the workforce. The Oxford Martin Commission for Future Generations (2013) suggests that graduates desire for full employment in their chosen discipline such as built environment areas may require revision. They cite evidence of movement towards a more fluid employment relationship, with individuals holding portfolios of skills that match work activities, including adaptive thinking, disciplinary literacy, STEM competencies, quantitative thinking skills etc. As one student noted:

"I am definitely more motivated now and can see this being of benefit to my future jobsthere are things that I learnt here, like explaining what the structure should be built like, that I was able to show I knew something and then to get ideas from the others about making it happen. That was an important skill I think"

The course had a total of 42 students, of whom about $20 \%$ were built environment students across the second year of their AQF 5 studies. This indicates the limitations of the results, given the small sample size, the stage of the students' studies and the elective nature of the course. However, the evident change in skill development through the exposure to $21^{\text {st }}$ century STEM skills as self-reported by the students in the interviews, indicates benefits and obvious advantages for built environment students.

\section{Conclusion}

The benefit to all students of a flexible, relevant, $21^{\text {st }}$ century STEM skill learning opportunity is immeasurable. In a growing competitive market, the learning and teaching opportunities and experiences provided to students are becoming increasingly critical to the future of universities. Graduate lifelong learning and employability is at the heart of university business. Built environment students in this course benefitted from an informed, flexible, industry-relevant pedagogy built upon $21^{\text {st }}$ century STEM skills that matched their experiences of a globalised world. Whilst there is still a place for the existing discipline-based approaches, as Williams (2011) notes, the pressing need for an integrated $21^{\text {st }}$ century STEM skill approach that positions all students and learners for employability and lifelong learning futures is escalating. The results from students in this sample indicate that students themselves are aware of the value of such integration. To enable all students and remain competitive, built environment disciplines must examine $21^{\text {st }}$ century STEM skill learning opportunities to acknowledge potential for improved activity in current curricula. The challenge is clear and exciting.

\section{References}

Barber, M, Donnelly, K, Rizvi, S,(2013) An Avalanche is coming: Higher education the revolution ahead, Institute for Public Policy Research.

Binkley, M., Erstad, O., Herman, J., Raizen, S., Ripley, M., Miller-Ricci, M., \& Rumble, M. (2012). Defining twenty-first century skills. In Assessment and teaching of 21 st century skills (pp. 1766). Springer Netherlands.

Blackley S \& Howell J ( 2015) A STEM narrative- 15 years in the making. Australian Journal of Teacher Education, 40 ( 7), p.8-9.

Callander S., (2015) The strategic imperative: Australia's place in the global labour market in 
CEDA (2015) Australia's Future Workforce, Committee for Economic Development of Australia Melbourne.

CSIRO -Hajkowicz SA, Cook H, Littleboy A (eds)(2012) Our Future World: Global megatrends that will change the way we live. CSIRO, Australia.

Deloitte - Kane, G. C., Palmer, D., Phillips, A. N., Kiron, D., \& Buckley, N. (2015). Strategy, not technology, drives digital transformation. MIT Sloan Management Review and Deloitte University Press. ( 2015)

Finkle A., (2016) STEM trained and job ready http://www.chiefscientist.gov.au/2015/08/occasional-paper-stem-trained-and-job-ready/ viewed 21 /09/16

Freeman, 2013; Gallagher, S \& Garrett, G 2013, Disruptive Education: Technology-Enabled Universities http://apo.org.au/node/35927 viewed 7/10/15

Frey, C. B., \& Osborne, M. A. (2013). The future of employment: how susceptible are jobs to computerisation viewed 7/10/2013.

Gratton L., (2015) Reshaping work for the future in CEDA (2015) Australia's Future Workforce, Committee for Economic Development of Australia, Melbourne

Healy, J, Mavromaras, K \& Zhu R 2013, 'The STEM labour market in Australia', A consultant report securing Australia's future STEM: country comparisons, ACLA, Melbourne.

Lantz, 2009 Science, technology, engineering, and mathematics (STEM) education: What form? What function? University of South Carolina,

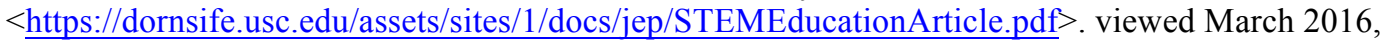

McKenzie F., (2015) Megatrends and Australia's future: Older and wiser? In CEDA Australia's Future Workforce, Committee for Economic Development of Australia, Melbourne

McLaughlin, P., Kennedy, B., (2015). The STEM Ecosystem, Chapman Publishing, Victoria Montt, G 2016, 'What skills do employers want?', OECD Skills and Work, $<$ https://oecdskillsandwork.wordpress.com/2016/03/23/what-skills-do-employers-want/> viewed June 2016 , 10-09-16

Navitas ( 2016) Learning in Higher Education http://www.navitas-professional.edu.au/ viewed

Organisation for Economic Co-operation and Development (OECD) (2014). Over-Qualified or Under-Skilled: A Review of Existing Literature, OECD Social, Employment Working Papers, No. 121, Paris. Canberra.

Office Chief Scientist ( 2016), Australia's STEM workforce, Office of the Chief Scientist,

Oxford Martin Commission. (2013). Now for the long term: The report of the Oxford Martin Commission for future generations. Oxford. UK

PWC ( 2016) Australia's national agenda http://www.pwc.com.au/publications/insights.html viewed $23 / 10 / 16$

Sabelli, N. H. (2006). Complexity, technology, science, and education. The Journal of the Learning Sciences, 15(1), 5-9. Canberra

Siekmann G \& Korble P, (2016) Defining STEM skills. NCVER Commonwealth of Australia, Canberra.

West ( 2012) West, M 2012, STEM education and the workplace, Office of the Chief Scientist,

Williams, C., Gannon, S., \& Sawyer, W. (2013). A genealogy of the 'future': antipodean trajectories and travels of the ' 21 st century learner'. Journal of education policy, 28(6), 792-806.

World Economic Forum 2015, New vision for education: unlocking the potential of technology, World Economic Forum, Geneva. 